\title{
BREASTFEEDING SELF EFFICACY DAPAT MENINGKATKAN PRODUKSI ASI PADA IBU POST PARTUM
}

\author{
Lutfiana Puspita Sari, Lusinta Agustina \\ Poltekkes Kemenkes Surakarta Jurusan Kebidanan
}

\begin{abstract}
Background : The Confidence, perception and calmness of post-partum mothers can affect the breastmilk production. Women who have low anxiety will have greater self efficacy indeed belief that breast milk production is sufficient for the baby's needs. Method: This was a quantitative research with survey design. The population in this study was all post-partum mothers who gave birth on normal process. The sample in this study was all post-partum mothers who were giving birth normally at the Independent Practice of Midwives at the Prambanan Health Center, Klaten. The analysis of this study used the Fisher Exact test. Result : There was a significant effect between breastfeeding self efficacy on the amount of breastmilk production ( $p$ value $=0.03)$, breastfeeding self efficacy on the process of breastmilk production $(p$ value $=0.01)$. Conclusion : Breastfeeding self efficacy influences the amount and process of breastmilk production for post-partum mothers
\end{abstract}

Keywords: Breastfeeding self efficacy, Breastmilk production, Post-Partum mothers

\section{PENDAHULUAN}

Deklarasi Innocenti tahun 1990 di Florence Italia mengamanatkan pentingnya mengkampanyekan Air Susu Ibu (ASI) sebagai bagian penting dari upaya perlindungan, promosi, dan dukungan menyusui. Untuk meningkatkan kesadaran semua pihak tentang pentingnya ASI bagi bayi dan diperlukannya dukungan bagi ibu dalam mencapai keberhasilannya menyusui bayinya, setiap minggu pertama bulan Agustus setiap tahun dijadikan sebagai 'Pekan ASI' (Kemenkes, 2017).

Asi ekslusif memiliki manfaat yang besar terhadap optimalisasi tumbuh kembang dan daya tahan tubuh anak. Namun faktanya masih banyak bayi yang tidak mendapatkan haknya untuk diberikan nutrisi terbaik yaitu ASI. Berdasarkan data pemantauan status gizi di Indonesia tahun 2017, cakupan pemberian ASI ekslusif selama 6 bulan di Indonesia masih sangat rendah yaitu $35.7 \%$. Angka ini masih jauh dari target cakupan ASI eksklusif pada tahun 2019 yang ditetapkan oleh WHO maupun Kementerian Kesehatan yaitu $50 \%$. Masih ada sekitar $64.3 \%$ bayi yang tidak mendapatkan ASI secara eksklusif selama 6 bulan pertama kelahirannya.

Rendahnya cakupan ASI ekslusif di Indonesia salah satunya disebabkan karena kepercayaan diri ibu yang rendah serta kecemasan yang tinggi untuk menyusui. Adanya persepsi ibu terkait ASI tidak cukup untuk memenuhi kebutuhan bayi, hal ini dipicu oleh motivasi dan kesadaran yang rendah untuk menyusui (Otsuka et al., 2008).

Rasa khawatir dan perasaan lain yang kurang menyenangkan merupakan salah satu tanda dari kecemasan. Biasanya perasaan ini disertai oleh ketidakpercayaan diri dalam menghadapi 
masalah. Perasaan tidak percaya diri dalam menghadapi suatu masalah membuat seseorang menjadi cemas dengan apa yang akan dihadapinya sehingga patut diduga bahwa efikasi diri mempengaruhi kecemasan seseorang.

Berdasarkan hasil studi pendahuluan yang dilakukan pada bidan praktek mandiri di wilayah kerja puskesmas Prambanan pada tanggal 2 Maret 2018 didapatkan hasil bahwa jumlah persalinan selama bulan Januari sampai dengan Desember 2017 tercatat ada 429 persalinan tanpa memandang paritasnya. Telah dilakukan wawancara terhadap 15 ibu post partum baik primipara maupun multipara untuk mengetahui kecemasan dan kepercayaan diri ibu untuk menyusui, didapatkan hasil bahwa 10 diantaranya mengalami kecemasan ringan serta memiliki kepercayaan diri rendah, serta 2 diantaranya mengalami kecemasan sedang. Kecemasan yang dialami oleh ibu tersebut disebabkan oleh berbagai macam alasan diantaranya adalah merasa cemas jika ASI nya tidak cukup untuk bayinya, pengalaman menyusui yang gagal, sakit ketika bayinya menghisap puting susu ibu, serta tidak percaya diri dalam memberikan ASI.

Hal inilah yang mendorong peneliti sehingga perlu dilakukan penelitian tentang pengaruh kecemasan dan breastfeeding self efficacy terhadap produksi ASI pada ibu post partum.

Penelitian ini bertujuan untuk mengetahui pengaruh kecemasan dan breastfeeding self efficacy terhadap produksi ASI pada ibu post partum.

\section{METODE PENELITIAN}

Penelitian ini termasuk jenis penelitian deskriptif analitik dengan pendekatan cross sectional (potong lintang). Dengan pendekatan potong lintang, semua variabel yang diteliti baik variabel independen maupun dependen diukur pada saat yang sama.

Populasi pada penelitian ini adalah seluruh ibu post partum yang bersalin secara normal di Bidan Praktek Mandiri Wilayah kerja Puskesmas Prambanan, Klaten. Teknik pengambilan sampel dengan menggunakan purposive sampling. Perhitungan besar subjek penelitian ini menggunakan "rule of thumb" yaitu subjek penelitian minimal 30 orang subjek untuk setiap variabel (Murti, 2013). Penelitian ini menggunakan 60 subjek penelitian. Subjek penelitian semua ibu post partum yang bersalin secara normal pada 48 jam pertama baik primi maupun multi di bidan praktek mandiri wilayah kerja Puskesmas Prambanan, Klaten.

Pengumpulan data, breastfeeding self efficacy diukur dengan skala BSES-SF dengan 14-item yang dikembangkan untuk mengukur kepercayaan menyusui dengan nilai skor berkisar antara 14 sampai 70 , dengan skor yang lebih tinggi menunjukkan lebih baik self-efficacy dalam menyusui.

Produksi ASI diukur dengan menggunakan cek list tentang kecukupan produksi ASI dilihat dari ibu maupun bayi berdasarkan kriteria dari utami roesli serta diukur jumlahnya dengan menggunakan gelas ukur dalam sekali perah selama 30 menit pada kedua payudara pada 48 jam pertama pasca persalinan.

Variabel breastfeeding self efficacy, dan produksi ASI diukur pada satu waktu dan secara bersamaan.

\section{HASIL PENELITIAN}

Hasil karakteritistik subjek penelitian pada tabel 1 menunjukkan dari 
60 subjek penelitian berdasarkan karakteristik, kriteria, frekuensi, dan persentase. Sebagian besar subjek penelitian berusia 20-35 tahun yaitu sebanyak 51 responden (85\%).

Untuk kategori pendidikan, sebagian besar subjek penelitian berpendidikan SMA-Perguruan tinggi sebanyak 47 responden $(78.30 \%)$.

Berdasarkan dari kriteria pendapatan subjek penelitian yang memiliki pendapatan dibawah Upah Minimum Regional (UMR) dan diatas UMR masing-masing seimbang sebanyak 30 responden $(50 \%)$.

Untuk lingkar lengan atas (LILA) yang dikaitkan dengan kecukupan nutrisi pada ibu post partum sebagian besar subjek penelitian memiliki LILA $\geq 23.5$ sebanyak 54 responden (90\%).

Untuk paritas (ibu yang pernah melahirkan) sebagian besar subjek penelitian merupakan paritas multi (pernah melahirkan lebih dari 1x) sebanyak 34 responden $(56.70 \%)$.

\section{Tabel 1. Karakteristik Subjek}

\section{Penelitian}

\begin{tabular}{cccc}
\hline Karakteristik & Kriteria & n & \% \\
\hline Umur & $<20$ tahun & 1 & 1.70 \\
& $20-35$ tahun & 51 & 85.00 \\
& $>35$ tahun & 8 & 13.30 \\
& & & \\
Pendidikan & SD-SMP & 13 & 21.70 \\
& SMA-Perguruan & 47 & 78.30 \\
& Tinggi & & \\
Pendapatan & $<$ UMR & 30 & 50.00 \\
& $\geq$ UMR & 30 & 50.00 \\
Nutrisi/LILA & $<23.5$ & 6 & 10.00 \\
& $\geq 23.5$ & 54 & 90.00 \\
Paritas & Primi & 26 & 43.30 \\
& Multi & 34 & 56.70 \\
& & & \\
& & &
\end{tabular}

\section{Analisis Bivariate}

Variabel independen pada penelitian ini adalah breastfeeding self efficacy. Variabel dependen adalah produksi ASI. Uji statistic yang digunakan adalah uji
Fisher Exact karena variabel independen dan dependen mempunyai skala kategorik.

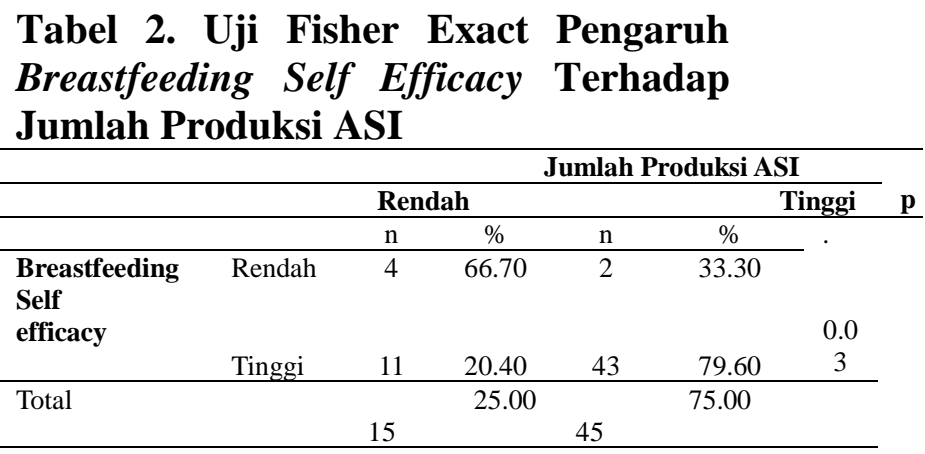

Tabel 2 menjelaskan pengaruh breastfeeding self efficacy terhadap produksi ASI dengan uji fisher. Uji bivariate ini untuk mengukur kekuatan hubungan dan signifikansi hubungan antara breastfeeding self efficacy dengan produksi ASI. Breastfeeding self efficacy berpengaruh terhadap produksi ASI yang ditunjukkan dengan nilai p $0.03<0.05$.

\section{Tabel 3. Uji Fisher Exact Pengaruh Breastfeeding Self Efficacy Terhadap Proses Produksi ASI}

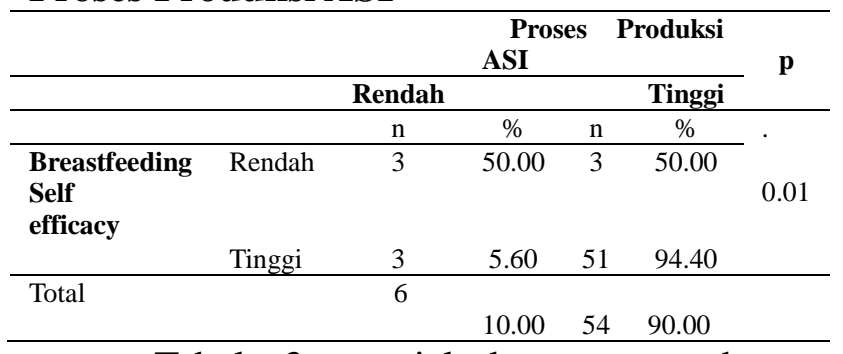

Tabel 3 menjelaskan pengaruh breastfeeding self efficacy terhadap proses produksi ASI dengan uji fisher exact. Uji bivariate ini untuk mengukur kekuatan hubungan dan signifikansi hubungan antara breastfeeding self efficacy dengan proses produksi ASI. Breastfeeding self efficacy berpengaruh terhadap proses produksi ASI yang ditunjukkan dengan nilai $\mathrm{p} 0.01<0.05$. 


\section{PEMBAHASAN}

Hasil penelitian menunjukkan bahwa sebagian besar responden berusia 20-35 tahun. Hal ini sesuai dengan Depkes (2009) bahwa wanita subur adalah wanita usia 15-49 tahun dengan keadaan organ reproduksi berfungsi dengan baik, baik dengan status belum kawin, kawin maupun janda. Sehingga pada usia tersebut tergolong dalam kondisi aman untuk hamil dan melahirkan. Reproduksi sehat untuk hamil dan melahirkan adalah usia 20-35 tahun jika terjadi kehamilan di bawah atau di atas usia tersebut maka akan dikatakan berisiko dan dapat berpengaruh terhadap proses persalinan dan laktasi (Manuaba, 2010). Selain itu ibu post partum yang masih berusia produktif akan dapat mengembangkan konsep diri yang menyenangkan, sehingga dapat menyesuaikan diri dengan baik.

Kepercayaan diri untuk menyusui sangat berpengaruh terhadap jumlah produksi ASI. Ibu yang memiliki kepercayaan diri yang tinggi untuk menyusui akan menghasilkan produksi ASI baik jumlah dan prosesnya lebih baik dibanding dengan ibu yang memiliki kepercayaan diri yang rendah untuk menyusui. Breastfeeding self efficacy berpengaruh pada respons individu berupa pola pikir, reaksi emosional, usaha dan kegigihan serta keputusan yang diambil. Self efficacy yang rendah dalam hal menyusui dapat menyebabkan persepsi dan motivasi yang negatif (Bandura, 1994; Denis, 2010).

Ibu yang memiliki kepercayaan diri yang tinggi akan menumbuhkan semangat dan kegigihan dalam menyusui bayinya yang dibuktikan dalam seringnya frekuensi untuk menyusui bayinya. Kepercayaan diri merupakan suatu keyakinan yang dimiliki seseorang bahwa dirinya mampu berperilaku seperti yang dibutuhkan untuk memperoleh hasil seperti yang diharapkan (Bandura, 1977).

Kepercayaan diri untuk menyusui merupakan salah satu faktor yang dapat berdampak terhadap produksi ASI yang dihasilkan. Bandura mengungkapkan bahwa individu yang memiliki self efficacy tinggi akan mencapai suatu kinerja yang lebih baik karena individu ini memiliki motivasi kuat, tujuan yang jelas, emosi yang stabil dan kemampuannya untuk memberikan kinerja atau aktivitas atau perilaku sukses.

Self efficacy ibu dalam menyusui lebih dikaitkan dengan keyakinan ibu bahwa produksi ASI cukup sesuai dengan kebutuhan bayi, seberapa besar usaha yang ibu lakukan untuk mendukung proses menyusui dan bagaimana upaya yang ibu lakukan ketika mengalami kesulitan pada saat menyusui. Namun sebaliknya ketika ibu mengalami kecemasan atau gejala depresi post partum akan menurunkan tingkat self efficacy ibu untuk menyusui hal ini akan berdampak terhadap produksi ASI yang dihasilkan serta menyebabkan kegagalan dalam menyusui (Dennis, 2009).

Berbagai penelitian telah breastfeeding self efficacy terhadap proses menyusui dan menunjukkan hasil bahwa breastfeeding self efficacy merupakan faktor penting yang berhubungan dengan inisiasi, durasi dan menyusui secara ekslusif (McQueen, 2011).

Hormon prolaktin dan oksitosin adalah hormon yang berpengaruh secara langsung terhadap produksi ASI. Ibu yang memiliki kepercayaan diri yang kuat untuk menyusui bayinya, akan memiliki motivasi yang kuat untuk sering menyusui. Frekuensi bayi dalam menyusu 
menyebabkan impuls sensory dari putting sampai ke otak sehingga sebagai tanggapan kelenjar pituitari dari lobus anterior mensekresi prolaktin dan lobus posterior mensekresi oksitosin. Ketika bayi menyusu, maka kadar prolaktin di dalam darah meningkat.

Selama beberapa minggu pertama setelah melahirkan semakin bayi sering menyusu dan merangsang putting susu ibu maka kadar prolaktin semakin tinggi sehingga ASI yang dihasilkan juga semakin banyak. Pada minggu awal pertama menyusui seringkali terjadi perubahan psikologis pada ibu post partum (WHO, 2009).

Perubahan psikologis tersebut dapat berpengaruh terhadap motivasi dan kepercayaan diri ibu untuk menyusui. Ibu yang memiliki self efficacy (kepercayaan diri) yang tinggi dapat mengatasi hambatan yang terjadi pada minggu awal post partum dibandingkan dengan ibu yang memiliki self efficacy yang rendah (Brockway et al., 2018).

Ibu yang memiliki kepercayaan diri yang tinggi untuk menyusui akan memiliki keyakinan sehingga dapat mengatur dan mengupayakan untuk dapat berperilaku menyusui bayinya sesuai dengan kebutuhan bayi serta dapat memutuskan untuk bisa memberikan ASI ekslusif atau tidak kepada bayinya (Deborah\&Rebecca, 2009).

Kepercayaan diri dan keyakinan yang kuat akan mendorong seseorang untuk berperilaku sehingga mencapai tujuan yang diinginkan. Keyakinan tersebut dapat mempengaruhi ASI yang dihasilkan. Keyakinan yang dimiliki ibu menyusui dapat meningkatkan motivasinya untuk mengatur durasi dan pola menyusui serta melakukan tindakan yang dibutuhkan agar dapat menyusui bayinya dan bagaimana supaya ASInya lancar sehingga berhasil ASI ekslusif dan cukup sesuai kebutuhan bayi.

Ibu yang memiliki self efikasi yang rendah lebih rentan untuk menghentikan menyusui secara dini karena mereka berkeyakinan bahwa produksi ASI tidak cukup untuk memenuhi kebutuhan bayi. Ketika terjadi penyapihan secara dini maka produksi ASI semakin lama semakin berkurang dan bahkan tidak berproduksi lagi karena tidak ada rangsangan dari bayi untuk menghisap puting.

Persepsi dan keyakinan ibu yang rendah menyebabkan ibu memtuskan untuk melengkapi proses penyusuan dengan memberikan susu formula kepada bayi, terhentinya proses menyusui menyebabkan tidak ada lagi rangsangan dari bayi menghisap putting susu ibu sehingga tidak adanya rangsangan untuk sekresi hormon prolactin dan oksitosin berproduksi. Hal inilah yang menyebabkan produksi ASI berkurang (Mannion\&Deborah, 2012). Kurangnya kepercayaan diri ibu sering juga dikaitkan dengan persepsi frekuensi menyusui yang kurang, adanya keyakinan produksi ASI terlalu sedikit tidak cukup untuk kebutuhan bayi serta membatasi frekuensi dan lamanya menyusui. Hal ini semakin membuat produksi ASI berkurang bahkan dapat terhenti (Kent et al., 2015).

\section{KESIMPULAN DAN SARAN}

Karakteristik subjek penelitian untuk usia, sebagian besar responden $(85 \%)$ berada pada usia reproduktif sehingga ASI dapat berproduksi dengan maksimal, jika tidak ada factor-faktor tertentu yang dapat menghambat produksi ASI. Salah satunya adalah kepercayaan dan keyakinan diri ibu untuk menyusui. 
Breastfeeding self efficacy efektif untuk meningkatkan proses dan jumlah produksi ASI. Hasil analisis dengan Fisher Excact memperlihatkan ada pengaruh yang signifikan antara breastfeeding self efficacy terhadap proses dan jumlah produksi ASI yang dihasilkan.

Breastfeeding self efficacy (kepercayaan diri untuk menyusui) perlu ditanamkan sejak kehamilan oleh tenaga kesehatan khususnya bidan dan dokter yang dekat dengan ibu hamil ketika melakukan pelayanan antenatal care, sehingga dari awal (kehamilan) ibu sudah memiliki keyakinan dan kepercayaan diri yang kuat untuk menyusui dan memberikan ASI ekslusif.

Ibu yang memiliki keyakinan dan kepercayaan diri yang kuat sejak kehamilan akan berperilaku positif sehingga mereka akan berusaha melakukan sesuatu untuk mencapai tujuannya dalam hal ini akan berperilaku bagaimana supaya produksi ASI cukup sesuai dengan kebutuhan bayi sehingga sukses dalam memberikan ASI ekslusif.

Dukungan dari kelurga terutama suami sangat penting dan dibutuhkan dalam hal ini, sehingga ibu semakin termotivasi untuk menyusui baik frekuensinya maupun durasi dalam menyusui.

Sugesti negatif yang tertanam dalam pikiran ibu bahwa produksi ASI tidak cukup dan ASI nya kurang harus direprogramming dengan sugesti positif yang sudah harus dilakukan sejak usia kehamilan trimester III.

Tenaga kesehatan dalam memberikan pelayanan kesehatan sebaiknya harus secara komprehensif dan benar-benar melakukan pendekatan ibu hamil serta melakukan pendidikan kesehatan terkait memberikan support kepada ibu hamil agar kelak ketika sudah melahirkan dapat memberikan ASI ekslusif kepada bayinya serta mengajarkan bagaimana menanamkan sugesti positif terkait keberhasilan menyusui sejak dari kehamilan.

Untuk penelitian selanjutnya dalam mengukur proses dan jumlah produksi ASI sebaiknya menambahkan variabel yang diteliti tidak hanya self efficacy dan kecemasan saja, melainkan banyak factor yang bisa diteliti terkait dengan proses dan jumlah produksi ASI.

\section{DAFTAR RUJUKAN}

Bandura, A. (1977). Self-efficacy: Toward a unifying theory of behavioral change. Psychological Review, 84(2), 191-215

Brockway M, Karen MB, Eloise C, Khalid A (2018). Breastfeeding self efficacy and breastmilk feeding for moderate and late preterm infants in the family integrated care trial : a mixed methods protocol. International breastfeeding journal vol. 13 (29)

Cox EQ, Stuebeb A, Pearsona B, Grewena $\mathrm{K}$, Rubinowa D, and Meltzer BS (2015). Oxytocin and HPA stress axis reactivity in postpartum women.

Psychoneuroendocrinology. 55:164-172.

Deborah MS, Rebecca G (2009). Breastfeeding Self Efficacy in women of African Descent. JOGNN (38) : 230-243

Dennis, C. L., \& Faux, S. (1999). Development and psychometric testing of the Breastfeeding Self-Efficacy Scale. Research in Nursing \& Health, 22(5), 399-409 
Dennis CL, Karen M (2009). The relationship between infant feeding outcomes and post partum depression : A qualitative systematic review. Pediatrics ; 123; e 736

Depkes RI (2009). Profil Kesehatan Indonesia. Jakarta: Depertemen Republik Indonesia

Kent JC, Anna RH, Diana BL, Peter EH (2015). Impact Of Measuring Milk Production by Test Weighing On Breastfeeding Confidence In Mothers Of Term Infants. Breastfeeding Medicine. Clinical Research Vol 10(6). DOI: 10.1089/bfm.2015.002

Kemenkes RI (2017). Pedoman Penyelenggaraan Pekan ASI Sedunia (PAS) Tahun 2017. Sustaining Breastfeeding Together / World Breastfeeding Week (WABA)

Mannion C, Deborah M (2012). Breastfeeding Self- Efficacy and the use of prescription medication : A Pilot Study. Hindawi Publishing Corporation. Obstetrics and Gynekology International. Article ID 562704. doi:10.1155/2012/562704

Manuaba IBG, Chandranita M, Fajar M (2007). Pengantar kuliah obstetri. Jakarta: EGC

Murti, B (2013). Desain Dan Ukuran Sampel Untuk Penelitian Kuantitatif Dan Kualitatif Di Bidang Kesehatan. Yogyakarta : Gadjah Mada University Press

Otsuka K, Cindy LD, Hisae T, Masamine J (2008). The relationship between breastfeeding self efficacy and perceived insufficient milk among
Japanese mothers. JOGNN. (37) : 546-555

Stuebe AM, Karen G, Samantha MB (2013). Association Between Maternal Mood and Oxytocin Response to Breastfeeding. Journal of women's health. Volume 22 : Number 4.

WHO (2009). Infant and young child feeding. Model Chapter for textbooks for medical students and allied health professional. 